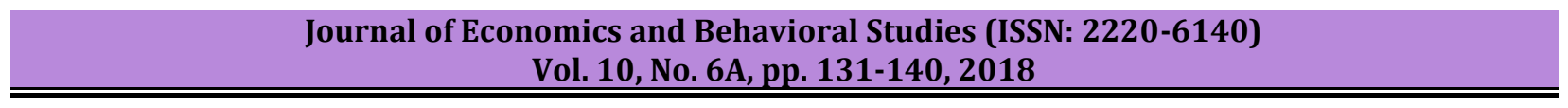

\title{
When Performance Management Fails: Attitudes and Perceptions of Staff at a Higher Education Institution
}

\author{
Odwa Mntonintshi ${ }^{1}$, Vuyokazi Mtembu ${ }^{2}$ \\ ${ }^{1}$ Durban University of Technology, South Africa \\ ${ }^{2}$ University of KwaZulu-Natal, Westville Campus, South Africa \\ mtembuv@ukzn.ac.za
}

\begin{abstract}
The implementation of Performance Management (PM) in an institution can come with barriers that affect its success rate. The aim of the study was to assess the perceptions and attitudes of staff towards the implementation of PM at a higher education institution. The research was undertaken at a higher education institution (HEI) in South Africa where employee performance suffered as a result of PM implementation challenges within the institution. The research study was exploratory and employed mixed methods, that is; quantitative and qualitative research methods. A survey questionnaire was administered to groups of university employees drawn through stratified random sampling. The strata groups were academics, administrators, and senior executive managers. Hundred questionnaires were distributed with eighty-three questionnaires returned. In qualitative research, a heterogeneous focus group interview was scheduled which involved twelve people. Results from the questionnaires indicated that respondents perceived PM process as lacking transparency, unaligned to employee rewards and development lacks objectivity from appraisers and poorly implemented due to lack of training for its users. Key themes that emerged from the focus group interviews revealed that the majority of participants perceived PM as a management punitive tool that is not developmental in orientation, a political tool that lacks objectivity and benefits only the employer. Furthermore, they articulated that it was not aligned with their rewards and development. It was therefore recommended that; proper design and implementation of the PM system is vital, fairness, training of all parties involved, moderation of results and providing effective feedback should be employed in PM, effective communication, transparency, consultation and shared benefits for all participants are key to ensuring a broadly supported PM within the institution.
\end{abstract}

Keywords: Performance Management, Perceptions, Attitudes, Higher education institutions, PM strategy.

\section{Background and Introduction}

Globally countries invest a lot of capital into universities, research and development in general (UNESCO, 2018; OECD, 2018), the expectation is that the return on investment will be greater in the form of a highly skilled national workforce and increase in the country's economic growth. As a result of poor PM processes, most universities fail to effectively carry out that national mandate and expectation (Mapesela \& Strydom, 2005; Seyama \& Smith 2015). Consequently, public higher education universities are encouraged by global society to improve their reporting frameworks in order to improve accountability and sustain equitable corporate governance mechanisms. Ter Bogt and Scapens, (2012:451) indicate that the drive of promoting more accountability in universities has been highly influenced by the rise of New Public Management (NPM), which has forced managers in public sector spaces to adopt business models when attempting to improve efficiency and productivity in public organisations. Universities also find themselves having to adopt such models including PM models to improve performance and ensure quality in their operations and in the calibre of professionals they produce.

The overall objective of the research study is to assess the attitudes and perceptions of employees towards the implementation of PM strategy at a higher education institution. The findings will enable the institution's management to have a broader understanding of what employees perceive as PM challenges that should be addressed, along with what they perceive to be PM support factors that should be nurtured for PM process to be effective. The study focused on an institution whose PM was not managed effectively and consequently employees resisted to participate in the process. The institution had a PM policy in place that was not effectively implemented within the institution and also faced challenges with regards to attitudes and perceptions of employees towards PM. As a result of poor PM, the quality of services rendered by the institution was compromised. The following broad question was addressed in the research study: Which important factors need to be considered when designing and implementing an effective PM strategy? 


\section{Literature Review}

PM in Higher Education Institutions: Definitions and Overview: Aguinis, Joo and Gottfredson (2011:504) define PM as "a continuous process of identifying, measuring, and developing the performance of individuals and teams and aligning performance with the strategic goals of the organisation". Ana-Maria, Constantin and Radu (2009:277) describe PM strategy as "an integrated approach to delivering sustained success to organisations by improving the performance of the people who work in them and by developing the capabilities of the teams and individual contributors". Freitas, Uren, Brewster and Gonçalves (2016:2) define performance measurement as "a process of quantifying the efficiency and effectiveness of an action which leads to performance". Adams (2013:384) maintains that universities, including graduates and professors, are expected by society to lead the development that affects people and the universe. The significant influence that universities have on future leaders, teachers and parents, shapes the actions of future generations. Furthermore, the influence of the public interest to universities is not only directly related to education, transfer of knowledge and research, but also towards the management of universities, which includes accountability for its performance (Adams, 2013:384). As of consequence, higher education institutions and all organisations in general have a pressure to perform optimally and effectively in their operations. This then means effective PM should take centre stage as the main tool to propel institutions towards optimal performance.

As argued by de Waal and Kerklaan (2015:85) Higher Education Institutions (HEIs) that have developed effective management control systems are fundamental to the development of a country. Therefore, most HEIs are under pressure to develop management control systems that will ensure they perform optimally. De Waal (2015:384) further states that the pressure for universities to improve their performance is influenced by many factors, including globalisation trends, since the HEIs have moved towards massification of their operations. Thus, market-driven transparency and accountability have been pushed as part of the education sector's agenda by increasing the regulations of central governments to monitor academic work through institutional, organisation management, utilisation of quality assurance, and 'evidence-informed practice' (Turk, 2016:21). As a result, all HEIs might be obligated to be efficient in their operations, expand the services they offer, as well as improve and diversify their operations. For example, massification as stated by de Waal (2015: 384) results in a large influx of new students both locally and internationally, with increasing student demands for better and more diverse education, funded through public funds acquired through taxes and government subsidies. Subsequently, it may seem that due to the high dependence of HEIs on public funding, budget constraints from governments globally have affected the sustainability of various institutions, including universities in South Africa. Likewise, de Waal and Kerklaan (2015:85) indicate that HEIs have to manage growing student numbers, arrange support for improved infrastructure and facilities, provide revised relevant curricula, source sustainable funding opportunities, and improve the attractiveness of graduates in the labour market.

It may appear that the increased focus on the development of effective PM systems in universities has also been highly influenced by constrained budgets and resources allocated to the public sector. Some of the resource challenges of universities are due to increased massification of higher education. Conversely, the South African higher education sector is impacted by a variety of socio-economic conditions that affect the allocation of resources by the government. Moreover, HEIs are required to direct resources towards strategies geared to improving support for staff and management capacity, along with promoting technology and innovation in teaching and learning processes (de Waal and Kerklaan, 2015:85). Furthermore, HEIs have to change and adapt their managerial models towards business-oriented practices in order to remain competitive and to survive. In addition, Stukalina (2015:70) finds that HEIs today also have to focus on ways of increasing their revenues, in entering the continuously evolving, global education market. Similarly, the institution under this study finds itself with challenges, such as increasing of revenue and decreasing costs that affect its sustainability. Therefore, these institutions in order to survive in the global market, have to ensure that their managers focus on decreasing the costs while improving performance to ensure that the university stays competitive, affordable and sustainable (Stukalina, 2015:70). Why do employees and senior executive managers resist the implementation of PM strategy? What are the attitudes and perceptions of employees and senior executive managers towards PM? 
Theoretical Framework: Systems theory (Figure 1) illustrates how PM is interdependent of other organisational variables and how it links up with organisational processes to create a desired output for the organisation. Figure 1 depicts that PM strategy is seen as an input that when implemented appropriately through approved systems by using adequate tools and instruments (in the throughputs section), will lead to the desired outputs. System thinking is important for implementation of PM in universities. Besides, universities are considered key agents in economic and social transformation (Kapetaniou and Lee, 2017:1). This proves that universities are regarded as open systems that are impacted by what happens in the societies they are in. Kapetaniou and Lee (2017:2) indicate that universities are constantly engaged with other role players in order to develop innovative processes to enhance the development of communities.

Figure 1: Systems Theory Diagram (Diagram Source: Author)

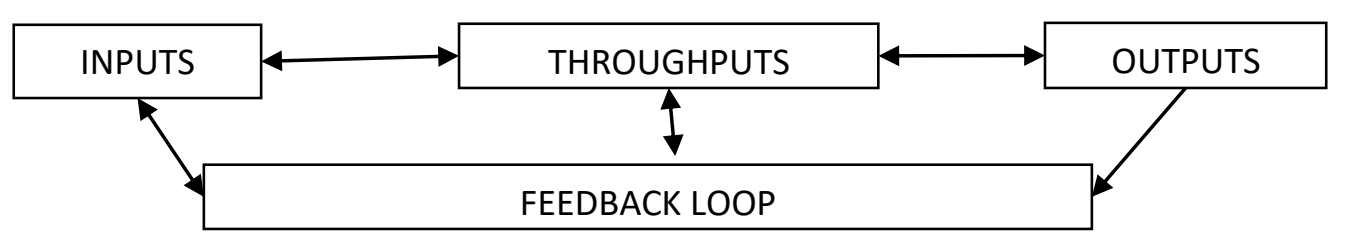

Systems thinking relate to PM formulation and implementation as PM is a sub-system of an organisation. Hutchinson (2013:2) explains that the main objective of PM is focused on improving othe verall performance of the organisation, which may be viewed from various wider perspectives at an organisational, sectoral, departmental, and personnel-manager level, as well as individual employee level. Therefore, PM is the key to drive execution of a business strategy as it is integrated in the business strategy and forms part of a system connected to other organisational systems, in order to lead to organisational effectiveness.

Performance Management Challenges and Perspectives in Higher Education Institutions: Gerrish (2016:48) finds that PM systems are so common they have even been allocated to public institutions with the expectation that they could improve the competitiveness of public institutions. As much as the motive for PM is good, unfortunately outcomes are not always as expected. Experience has revealed that in some if not most institutions PM fails to deliver because of multiple challenges the process usually encounters. To mention a few of the factors that lead to PM experiencing challenges; Kalman (2016:22) state that PM systems have a tendency to sometimes not improve the performance of public organisations but rather encourage behaviors that increase measured performance, while negatively affecting the actual performance of workers. In addition, some programmes in the public sector seem to experience difficulties in the use of performance measurement techniques and this includes HEIs. This is mainly due to the complexity of the roles they play, and where outputs or outcomes are difficult to quantify (Poister et al., 2013:626). Along the same lines, Kalman (2016:22) maintains that most people do not enjoy formulating and implementing a PM strategy. There are some workers that believe that PM systems are misguided, or that management poorly applied the PM system, and in some instances one finds arguments that PM systems are used for political gains within organizational settings (Kalman, 2016:22).

PM may be viewed by some managers as a tedious process that escalates problems between managers and employees. These and many more complexities in the design and implementation of PM results in its challenges in looking at another perspective towards a solution, Barr (2016:16) puts a possible way forward when she states that PM has been traditionally developed for manufacturing organisations where 'outputs are tangible' and consistent making it easier to control and not for non-manufacturing organisations where outputs are intangible and fluctuate. Universities are mainly focused on teaching and learning, research and engagement. These are the activities focused on intangible processes carried out by personnel of the university, leaving the question of whether PM strategies and systems are beneficial to the academic educational sector. This is the question that these institutions need to interrogate when planning their PM strategies in order to ensure that they design and implement PM systems that are relevant to the needs of a higher education institution. 
Another perspective on how HEIs worked in the past before introduction of strict and standardised PM systems; Simmons (2002:87), states that universities in the past (during the 1970s) adopted a 'laissez-faire' approach to the management of performance. For instance, the managers of universities delegated any form of management of performance to individual staff members, who subsequently demonstrated that staff were totally trusted and believed to perform to the best of their abilities and thus meeting organisational goals. Universities in the past operated through trust within an ethos that promoted high independence of academics and scholarship and valuing academic freedom and collegiality between academics and management (Simmons, 2002:87). On the other hand, during the 1980s, universities, as with most public sector entities, were forced to adapt their management control models due to economic pressures that threatened their sustainability; they were thus forced to become market driven and customer-focused by ensuring value for money to the public as a strategic direction to improve sustainability (Simmons, 2002:87). The various pressures, which include political, financial, and social justice issue influenced universities to change and improve how they manage their performance with the aim of assuring the public of their accountability.

Furthermore, government regulations have emphasised the standardisation of quality assurance in teaching and learning to ensure uniformity of practice (Simmons, 2002:88). Overall, Wilkes et al. (2011:23) comment that PM problems are inherent in any management system, as most people do not appreciate having their performance constantly monitored. It is important to note that any management system will pose some challenges to the design and implementation of a PM strategy in any organization. The thinking that PM leads to higher performance comes from the logic of goal clarification and performance monitoring across the organization in order to ensure the attainment of goals (Poister et al., 2013:626). After all, have been said and done organisations need to design and implement PM relevant to specific needs and context of that particular institution. The PM should be embedded in the strategic plan of the organization, which guides how outcomes will be regularly monitored to assist managers with useful information for better decision-making that will improve overall performance.

\section{Research Methodology}

A triangulation of mixed methods approaches combining quantitative and qualitative research methods was used. This in order to provide the researcher with corroboration, complete and comprehensive understanding of the phenomenon from all vantage point. The sample was selected using stratified random sampling. Stratified random sampling is used when various groups within the population have to be selected (Sekaran and Bougie, 2014:256). The study employed the sample size determination table by Krejcie and Morgan, developed in 1970, as a guideline to simplify the decisions for a representative sample size. A survey questionnaire was administered to the selected sample of employees. In a quantitative study, a sample of hundred respondents was selected from three categories that formed the strata groups; academics, administrators, and senior executive managers. These groups were selected to ensure that all employees from different levels and units within the institution were fully represented. Hundred questionnaires were distributed with eighty-three questionnaires returned.

The qualitative method consisted of open-ended questions. A heterogeneous focus group interview was conducted with twelve participants selected again from the three strata groups namely, academics, administrators and senior executive managers. A Likert scale type questionnaire in the quantitative study as well as interview schedules in qualitative study were used in data collection. To ensure data quality the researcher employed the methods of validity and reliability. According to Sekaran and Bougie (2014:225), validity measures how well an instrument that has been developed in the research study measures the particular concept it is intended to measure. As described by Sekaran and Bougie (2014:228), reliability focuses on the extent to which a measure has no bias or is error-free. Reliability ensures that the measurement is consistent every time it is applied. SPSS version 25 was used to analyse quantitative data and manual thematic analysis to analyse qualitative data collected. 


\section{Presentation and Discussion of Results from Quantitative Study}

Partnership in the Design and Implementation of a PM: Results revealed that there was not much partnership between employees and management in the design and implementation of PM strategy in the institution. As shown in figure 2 below, more than 60 percent of the respondents disagreed that there was a partnership between management and employees in the design and implementation of a PM strategy.

\section{Figure 2: Partnership in Design and Implementation of PM Strategy}

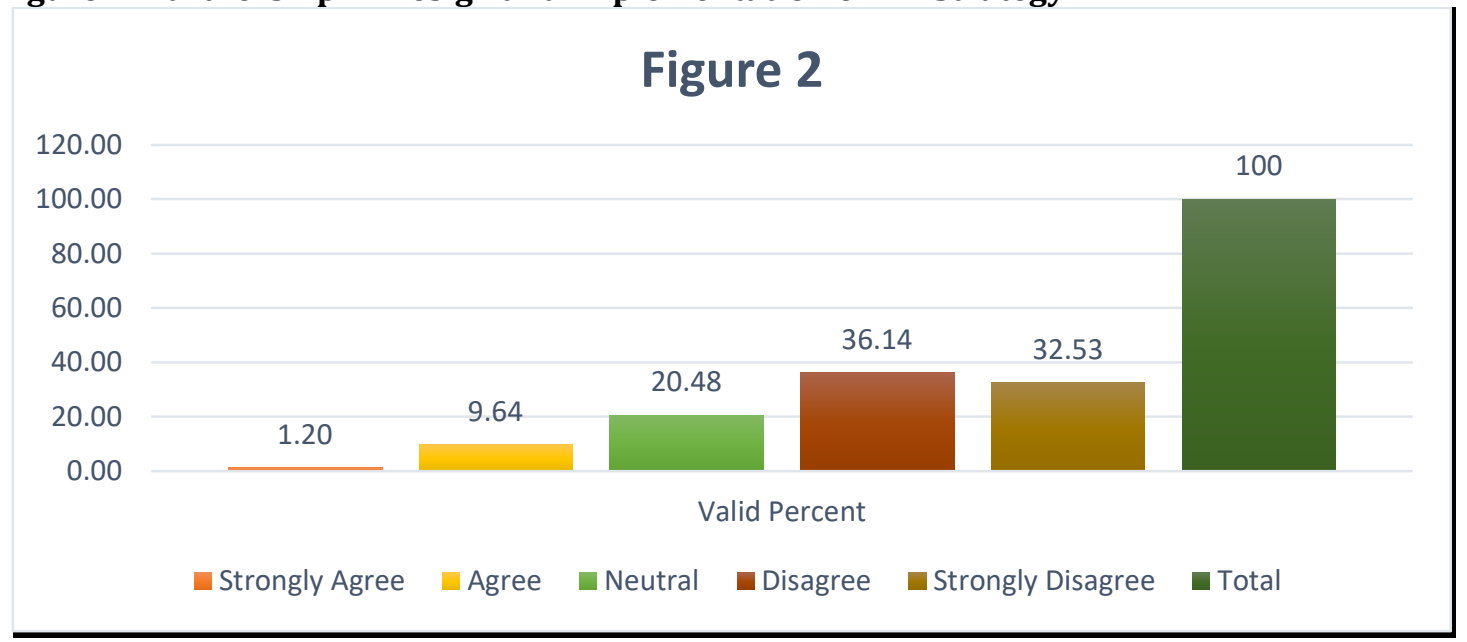

As stated by Thursfield and Grayley (2016:789) the ideology of PM is criticised for being embedded in the unitarist approaches where management tends to develop PM programme without taking into consideration the concerns and interests of employees. Unitarist ideology is seen to converse acceptability through propagating management control that does not support employee active involvement. The question/ concern raised by the results of this study is whether a collaborative design and implementation of a PM strategy play a vital role in shaping the attitudes and perceptions of employees towards PM. Judging by results of employee attitudes and perceptions in the organization under study, one can confidently conclude that collaboration in the design of PM does play a role in shaping employee attitudes and perception towards PM. Scholars agree that partnerships in the design and implementation of PM are vital to ensure its success as emphasised in the statements by the following; Türk (2016:19) views PM as consisting of regular information and communication consistently geared towards employee development, as well as the attempt to create an encouraging work environment. Hutchinson (2013:2) states that PM is generally portrayed as an integrated process in which managers engage with employees to set expectations, measure and review results, agree on improvement plans, and sometimes reward performance. Thursfield and Grayley (2016:789) further state that from the perspective of pluralism, the employment relationship is characterised by an imbalance between employers and labour, which results in unequal power relations and competing class interests that are dealt with through collective bargaining and collective solutions to individual problems.

Alignment of PM to Employee Rewards and Compensation: Results in figure 3 illustrate that 37, 35 percent of the respondents strongly agreed that their compensation and rewards are not tied to their performance standards. Another 37, 35 percent of the respondents agreed that their compensation and rewards are not tied to their performance standards. This means more than $75 \%$ of respondents stated that PM was not tied to their rewards and compensation. This then gives one an indication that PM in the institution was mainly done only as a compliance exercise and a policing tool for poor performers without providing any incentives for high performers. The above results complement what Seyama and Smith (2015) also observed in their study of PM and rewards at a South African HEI, they observed that "PM reward strategy not only have a limited effect in promoting high-performance behaviour, but was a cause of discontent due to implementation inconsistencies, nebulous award criteria, lack of transparency about ratings, and the negligible monetary value of the reward" (Seyama and Smith, 2015:1). Mapesela and Strydom (2005) in their study at three South African higher education institutions also emphasised that "Staff in all 
three institutions supported the linking of performance to pay. They further stated that; the complexities surrounding the linking of pay to performance was apparent from their study.

Figure 3: Alignment of Compensation and Rewards to Performance Standards

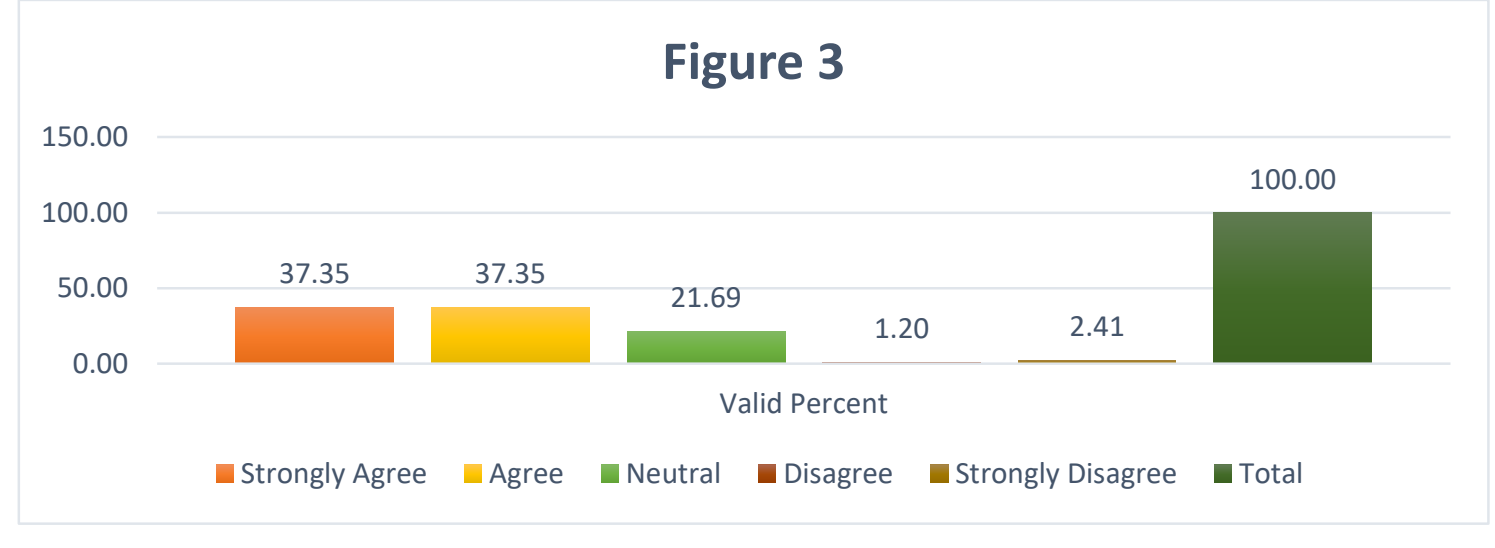

Training for Parties Involved in PM: Majority of respondents, which in this case was more than 60 percent of employees as shown in Figure 4 disagreed that they received any kind of training on PM processes. It was also clear that better integration was needed between the PM system and the promotion systems in the institutions" (Mapesela and Strydom, 2005:6)

\section{Figure 4: Training on PM Strategy}

\section{Figure 4}

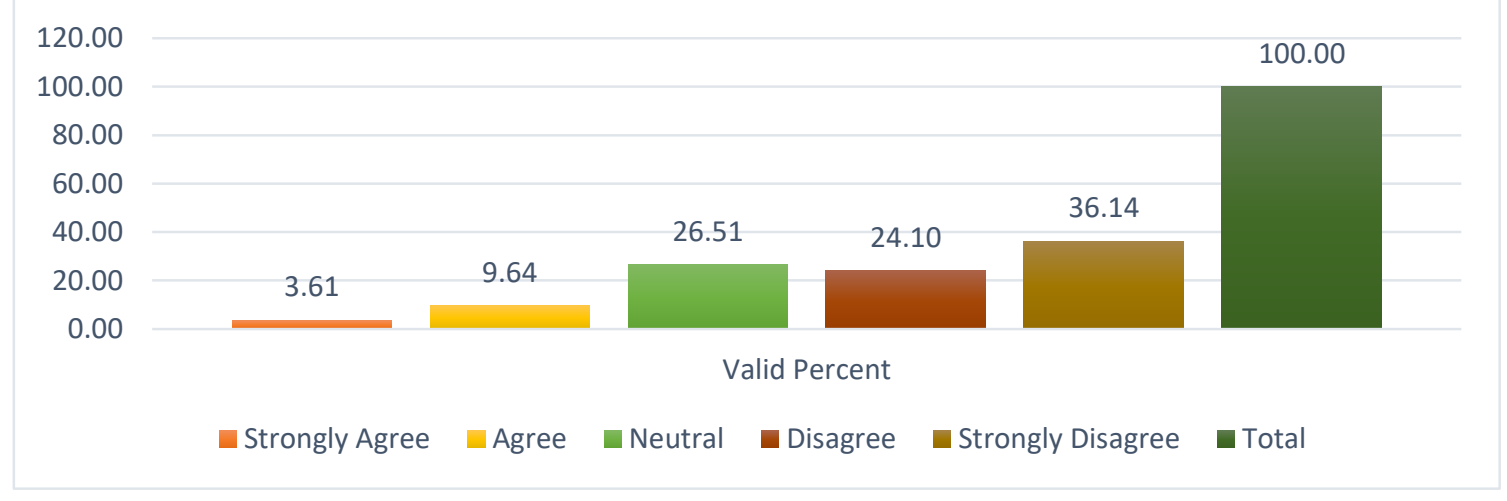

Falola, Osibanjo and Ojo (2014:161) state that organizational survival in the globally competitive environment is dependent on the firm's ability to train and develop its human capital so as to enhance creativity, as well as innovation that will improve performance, and competitive advantage. Communication and availability of training opportunities are the fundamental factors in the implementation of PM strategies. PM is regarded as most effective through management by objectives, whereby managers negotiate and agree on performance standards with employees. Effective human resource management has shifted from the view where people are considered as a variable cost to the view where people are regarded as a resource, and as social capital, that can be developed and can contribute to the company's sustained competitive advantage. The lack of existing programmes to build employee and managerial capacity, with which to conceptualise a PM strategy and design effective systems for measuring performance, negatively impacts on the organisational drive of implementing a PM strategy. The organisation should align its training and development plans to the PM strategy. Employees of the organisation are indispensable assets that create the firm's competitive advantage and training opportunities are able to help employees perform at their level best (Falola et al., 2014:161). 
Communication between Managers and Employees on PM Strategy: As reflected in figure 5, half (50 percent in total) of the respondents surveyed disagreed that open communication exists between managers and employees to implement PM strategy.

\section{Figure 5: Communication between Managers and Employees on PM Strategy}

\section{Figure 5}

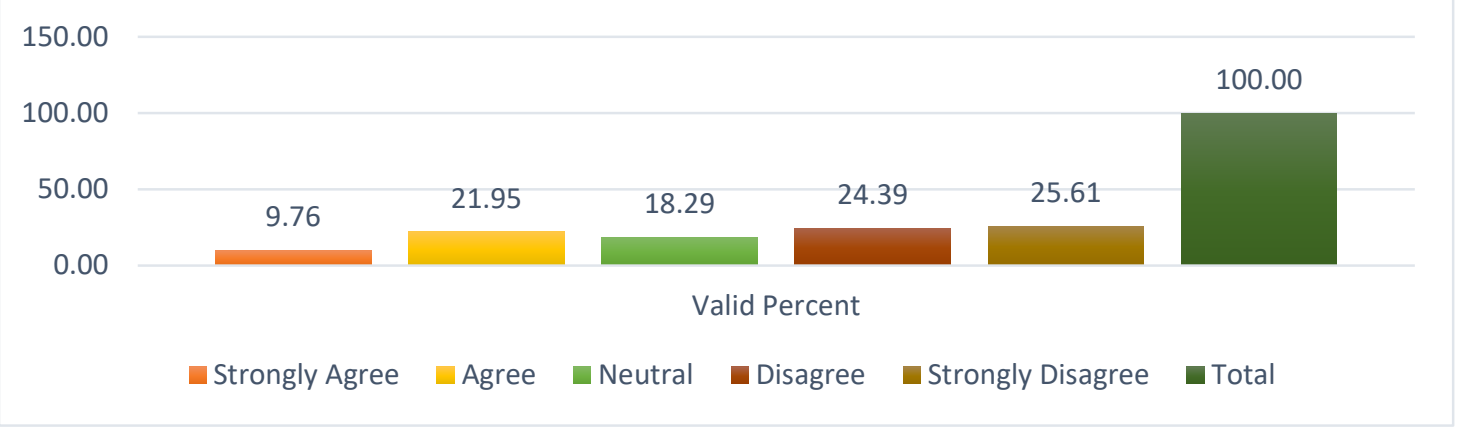

Effective communication between employees and managers is fundamental to ensure proper design and implementation of a PM strategy. This can be done in the form of open channels of communication, consultation forums with employees and their trade unions in which all stakeholders can be afforded an opportunity to have an input in the process. Daniela (2013) contends that a lack of communication and poor management of PM results in major challenges such as lack of skills and organizational culture that does not value information sharing. All parties involved in PM in the workplace should be free to talk about the PM strategy of the organisation to everyone, including managers and colleagues. There should be clear lines of communication for people to voice their concerns about the design and implementation of PM systems and processes. Kalman (2016:23) comments that in order for the PM programme to have integrity, senior management must communicate the standards up front, affording everyone the opportunity to participate in the dialogue. Transparency is fundamental to ensure that people know what is expected, earlier rather than later. Human capital buy-in is necessary in order to build teams that will work tirelessly to achieve the corporate strategy. Organisational communication represents the critical component in PM (Daniela, 2013).

Results from Qualitative Study: Five major themes emerged from interviews as indicated in table 1 below. These themes explicitly revealed employee attitudes and perceptions towards PM and reasons why employees resist the implementation of the PM process in the institution. These themes were also discussed during the focus group interviews and various sub-themes emerged from these discussions (Table 1). Feedback from participants was categorised in various sub-themes. Responses are outlined below in table 1 and discussed from section 1 below.

Table 1: Identified Themes and Sub-Themes from Focus Group Interviews

\begin{tabular}{ll}
\hline Themes & Sub Themes \\
\hline Employees fear of victimisation & Employee prejudiced \\
& Favouritism \\
& Dismissals \\
& Subjectivity \\
Lack of knowledge and understanding around PM & No transparency in management models \\
issues & PM standards vague \\
& $\begin{array}{l}\text { Poor communication channels between managers and } \\
\text { employees }\end{array}$ \\
No training programmes & $\begin{array}{l}\text { Lack of managerial training on PM } \\
\text { Lack of employee training on PM }\end{array}$ \\
& Lack of career planning and development \\
Compensation $/$ rewards not aligned to & Poor grading systems \\
\hline
\end{tabular}


performance

Partnerships on PM strategy implementation between management, labour and their trade unions and Council.
No performance rewards/incentives

No transparency on budget allocation for PM awards

No consultative forums between employer and labour (in the form of unions)

Poor communication on PM issues between managers and employees.

Fear of Victimisation: Keywords fear, victimisation, prejudice, intimidation were prevalent during focus group discussions. In their own words some participants stated the following; "The implementation of a PM strategy that is not effectively designed and implemented leads to some employees being prejudiced" (Interviewee 1, male) "Some employees are subjected to disciplinary proceedings due to poor performance and others even face dismissals" (interviewee 3, male) "If a manager does not like an employee for certain personal reasons they then tend to be biased and unfair in how they evaluate that employee's performance" (Interviewee 2, female) "The general perception amongst the workforce is that there are many CCMA cases that are based on poor performance standards which have never been agreed upon" (Interviewee 4, male) Thursfield and Grayley (2016:789) state that people in organisations find problems with PM as managers apply unitarist approaches to conceptualise and implement strategies for managing performance in the organisation. Workers are then forced to conform to developed systems and submit to the prevalent management control which drives PM though employees fear and victimisation.

Lack of Knowledge and Understanding about PM Strategy: Participants in the focus group interviews also revealed that all parties involved in the planning and implementation of PM including managers did not have efficient knowledge and capacity to implement PM effectively. In their own voices some participants stated the following: "Due to the little knowledge managers possess about PM strategy, their process of performance measurements is not transparent. Managers threaten employee's job security by using performance reviews" (Interviewee 6, female) "No consultation, collaboration and communication channels when it comes to setting of PM standards and there are no avenues available to assist employees who are poor performers to achieve the standards" (Interviewee 3, male) Kalman (2016:23) comments that in order for the PM programme to have integrity, senior management must be well equipped on PM through training, managers must also communicate the standards up front, affording everyone the opportunity to participate in the dialogue. Transparency is fundamental to ensure that people know what is expected, earlier rather than later. Human capital buy-in is necessary in order to build teams that will work tirelessly to achieve the corporate strategy. Organisational communication represents the critical component of PM.

Training of All Parties Involved in PM: Regarding training of parties involved in PM, focus group interviews revealed the following; "Managers have not been trained to implement PM strategy" (Interviewee 1, male) "Training and development is fundamental for the effective design and implementation of PM strategy" (Interviewee 10, female) "There are no employees that have received training and who have participated in the design and implementation of PM strategy" (Interviewee 4, male) The organisation should align its training and development plans to the PM strategy. Employees are indispensable assets that create the firm's competitive advantage and training opportunities are able to help employees perform at their level best (Falola et al., 2014:161). This places training as one of the key components towards the achievement of an efficient and effective PM.

Compensation and Benefits: Participants in the focus group interviews indicated that there was no link between PM and their rewards in their own words they stated the following; "The institution's grading system is not aligned with the PM strategy and employee pay is not tied with the current performance standards" (Interviewee 8, male) "There are no performance rewards, monetary and non-monetary" (Interviewee 3, male). Türk (2016:18) states that PM practices involve goal setting and planning, monitoring and evaluation, communication and feedback, as well as an appraisal of employees and compensation of employees based on their actual performance results. These findings are consistent with those of Seyama and Smith (2015) who also found that HoD's at a South African HEI were "sceptical of the PM as they view it as a business-oriented practice that is not compatible with the nature and objectives of higher education institutions with its reward strategy having a limited effect in promoting high performance behaviour, but is a 
cause of discontent due to implementation inconsistencies, nebulous award criteria, lack of transparency about ratings, and the negligible monetary value of the reward" Seyama and Smith (2015:1). These findings emphasise the significance of aligning pay to performance to ensure a fair and meaningful PM exercise in the organization.

Partnerships between Council, Management, Labour and their Trade Unions: On the area of partnerships and stakeholder collaborations, participants stated the following; "No consultative forums on PM" (Interviewee 10, female) "There is no signed agreement or memorandum of understanding between management and the concerned university stakeholders on PM" (Interviewee 1, male) Türk (2016:19) explains that PM is regarded as give-and-take system of job-related information. The employer through management and employee has an opportunity to express their wishes and ideas towards creating a relationship based on mutual benefits. The lack of employee involvement in the design of a system to manage their performance is a problem, as people in the workplace refuse to use frameworks, systems and processes which they did not participate in their development. The practice towards managing the performance of employees in an organisation is guided by the mutual relationship between employees, their unions and management.

It is important that employees are given the opportunity to express their views and wishes regarding information relative to their performance. Nonetheless, it is evident that PM strategies that fail have not been developed in collaboration with the employees, whose performance is monitored. It is held that managers always monitor workers as they want them to improve their performance (Barr, 2016:16). Nonetheless, most employees do not appreciate being monitored as they feel they are judged based on past performance data and this impacts employee job security, as well as relations built between managers and employees. The tools used in PM systems provide useful information that must be contextualised to the mission, aims and objectives of the organisation that are developed through the engagement of the diverse stakeholders (Secundo, Perez, Martinaitis and Leitner, 2017:3).

\section{Conclusion and Recommendations}

To facilitate progressive and productive PM system, institutions must ensure adequate consultation and communication with all stakeholders concerned regarding PM strategy to be implemented. Impeccable planning, design and implementation of the PM systems are vital for the PM to be successful. Openness, transparency and fairness in how PM is done also of huge significance training of all parties involved, moderation of results and providing effective feedback should be employed in PM. Involving external assessors, moderators and evaluators also assist in ensuring that PM is fair with minimum bias. Furthermore, a PM system aligned with employee compensation and rewards with shared benefits for all participants is key to ensuring a broadly supported PM within the institution. Significantly, it must be understood by all that PM is a development tool than a punitive one, the main purpose of PM should be to develop, grow and motivate employees to perform at their optimal best for the benefit of both the employee and the organization. PM as a strategy should lead to the development of an organisation-wide framework that connects the different systems and processes implemented across various organisational levels to effectively monitor and measure the performance of organisations. The fundamental element in improving and strengthening the value of PM management within the institutions lies in co-operation and collaboration between all the involved stakeholders. There is a need to provide organizational spaces for all stakeholders to discuss the existing PM policy, in order to revise the policy and make it relevant to the employee and organisational needs. Training and support have also been identified as fundamental managers would need to immediately take into consideration prior to introducing a PM strategy. 


\section{References}

Adams, A. C. (2013). Sustainability reporting and PM in universities: Challenges and benefits. Sustainability Accounting, Management and Policy Journal, 4(3), 384-392.

Aguinis, H., Joo, H. \& Gottfredson, R. K. (2011). Why we hate PM-and why we should love it. Business Horizons, 54(6), 503-507.

Ana-Maria, G., Constantin, B. \& Radu, C. (2009). The strategic PM process. Annals of Faculty of Economics, 4(1), 276-279.

Barr, S. (2016). Measuring people doesn't improve performance. Human Resources Magazine, 21(2), 6-17

Daniela, P. M. (2013). The interdependence between management, communication, compartmental behavior and performance. The Annals of the University of Oradea, Economic Sciences, 22, 1393-1401.

De Waal, A. \& Kerklaan, L. (2015). Developing an Evidence-Based Management Approach for Creating HighPerformance Higher Educational Institutions. Academy of Educational Leadership Journal, 19(3), 85.

Falola, H. O., Osibanjo, A. O. \& Ojo, S. I. (2014). Effectiveness of training and development on employees' performance and organisation competitiveness in the Nigerian banking industry. Bulletin of the Transilvania University of Brasov; Economic Sciences, 7(1), 161.

Freitas, Jr. V., Uren, V., Brewster, C. \& Goncalves, A. L. (2016). Ontology for performance measurement indicators' comparison. International Journal of Digital Information and Wireless Communications, 6(2), 87-97.

Gerrish, E. (2016). The Impact of PM on Performance in Public Organisations: A Meta-Analysis. Public Administration Review, 76(1), 48-66.

Hutchinson, S. (2013). Performance management: theory and practice. Kogan Page Publishers.

Kalman, L. (2016). Driving results through PM. Workforce Solutions Review, 21-26.

Kapetaniou, C. \& Lee, S. H. (2017). A framework for assessing the performance of universities: The case of Cyprus. Technological Forecasting and Social Change, 123, 169-180.

Morgan, K. (1970). Sample size determination using Krejcie and Morgan table.

Mapesela, M. L. E. \& Strydom, F. (2005). PM of academic staff in South African higher education: a developmental research project. In Conference; on Trends in the management of human resources in higher education.

OECD. (2018). Gross domestic spending on R\&D (indicator). doi: 10.1787/d8b068b4-en (Accessed on 04 June 2018)

Poister, T. H., Pasha, O. Q. \& Edwards, L. H. (2013). Does PM lead to better outcomes? Evidence from the US public transit industry. Public Administration Review, 73(4), 625-636.

Sekaran, U. \& Bougie, R. (2014). Research methods for business: A skill building approach. John Wiley \& Sons.

Seyama, S. M. \& Smith, C. (2015). Not worth the sweat": PM rewards at a South African university. Indo-Pacific Journal of Phenomenology, 15(2), 1-13.

Secundo, G., Perez, S. E., Martinaitis, Ž. \& Leitner, K. H. (2017). An Intellectual Capital framework to measure universities' third mission activities. Technological Forecasting and Social Change, 123, 229-239.

Simmons, J. (2002). An "expert witness" perspective on performance appraisal in universities and colleges. Employee Relations, 24(1), 86-100.

Stukalina, Y. (2015). Management in higher education: thinking and planning more strategically. Journal of Business Management, (10).

Ter Bogt, H. J. \& Scapens, R. W. (2012). PM in universities: Effects of the transition to more quantitative measurement systems. European Accounting Review, 21(3), 451-497.

Thursfield, D. \& Grayley, K. (2016). Exploring performance management in four UK trade unions. Employee Relations, 38(5), 789-804.

Türk, K. (2016). PM of Academic Staff and Its Effectiveness to Teaching and Research-Based on the Example of Estonian Universities. Trames: A Journal of the Humanities and Social Sciences, 20(1), 17.

United Nations Educational, Scientific and Cultural Organization. (2018). How much does your country invest in R\&D, [online] http://uis.unesco.org/apps/visualisations/research-and-development-spending/ [Accessed 04/06/2018], UNESCO Institute of Statistics.

Wilkes, J., Yip, G. \& Simmons, K. (2011). Performance leadership: managing for flexibility. Journal of Business Strategy, 32(5), 22-34. 